\title{
SOBRE O DISCURSO DA CONSTRUÇÃO DO CONHECIMENTO ${ }^{1}$ ON THE KNOWLEDGE CONSTRUCTION DISCOURSE
}

\author{
Kazue Saito Monteiro de Barros*
}

\begin{abstract}
Resumo: Muitos analistas dos gêneros textuais pleiteiam a existência de um domínio pedagógico, o que torna relevante definir quais gêneros o constituem e o que eles têm em comum. Os traços mais compartilhados por esses gêneros constituiriam as características mais básicas do domínio pedagógico. É nesse sentido que o presente trabalho se insere: busca identificar traços recorrentes em três formas de textos pedagógicos que circulam em contextos educacionais - redação de aluno, textos que ocorrem em livros didáticos, fala de professor. Antes da análise, reúne algumas observações sobre os critérios que têm sido usados por pesquisadores na caracterização de gêneros pedagógicos.
\end{abstract}

Palavras chave: discurso acadêmico; domínio discursivo; gêneros pedagógicos.

1 Trabalho apresentado no Encontro Internacional de Texto e Cultura, UFC, Fortaleza, 29/10 a 01/11/2008, no âmbito da mesa-redonda Os gêneros textuais em contextos educacionais, com os professores doutores Maria Elias Soares (coordenadora), Gilton Sampaio de Souza e Jean-Michel Adam. Em algumas passagens, retoma outros trabalhos desenvolvidos por mim, em diferentes ocasiões.

* PhD em Language \& Linguistics, pela Essex University, U.K. Professora associada da Universidade Federal de Pernambuco e bolsista de produtividade do CNPq. E-mail: kazuesaito@uol.com.br. 
BARROS, K. S. M. Sobre o discurso da construção do conhecimento

\section{Notas preliminares}

Este trabalho é parte integrante da pesquisa denominada Gêneros Textuais do Domínio Científico: um estudo comparativo, que vem sendo desenvolvida com o auxílio do CNPq e no contexto do Núcleo de Estudos Linguísticos da Fala e da Escrita - NELFE - da Universidade Federal de Pernambuco.

O programa de estudos que desenvolvo há algum tempo contempla uma série de gêneros discursivos do que tem sido chamado domínio pedagógico, incluindo uma gama variada de aulas e de textos que circulam nesse ambiente. No pressuposto da existência de um domínio pedagógico, a questão passa a ser, então, quais os gêneros que o constituem e o que eles têm em comum ${ }^{2}$. Em tese, o conjunto de características similares desses gêneros constituiria os aspectos mais fundamentais do domínio pedagógico.

Assim, o trabalho reporta-se a duas questões:

a) Quais seriam os critérios mais fortes para classificação de um gênero como pedagógico?

b) Quais seriam as características mais recorrentemente compartilhadas por gêneros pedagógicos?

Obviamente, não pretendo responder de forma completa a essas questões aqui, mas tentarei, com a brevidade que se faz necessária, identificar e comentar os critérios que, de forma explícita ou não, têm sido mais utilizados para a definição do que é "pedagógico". Comentários serão apoiados por dados da nossa pesquisa.

\section{Observações teóricas: perspectiva geral e conceitos}

O trabalho segue a perspectiva da relação entre fala e escrita, vistas como modalidades de uma mesma língua. A adoção da perspectiva significa que, do ponto de vista metodológico, os gêneros são trabalhados em oposição a outros afins, seguindo assim a recomendação de Biber (1988), entre outros, de que as comparações entre textos devem ser feitas com base em similaridades e não em características polares. Tal procedimento permite, por exemplo, a identificação da-

2 Com esta questão, não queremos pleitear uma noção rígida e fechada de gênero ou de domínio, conforme ficará evidente ao longo da exposição. 
quilo que os gêneros virtuais - no caso, do domínio pedagógico - têm de específico ou de semelhante com gêneros análogos da fala/escrita, pois até o momento não avançamos muito além de afirmações generalizadas.

\section{Domínio e domínio pedagógico}

Nos estudos sobre gêneros, o conceito de domínio discursivo é, às vezes, tratado de forma ainda preliminar, como uma categoria autoexplicativa, evocada para dar conta das semelhanças que, intuitivamente ou não, percebemos como enlaçadas no contexto de alguns gêneros. Quase sempre, na conceituação de domínio, recorre-se a exemplificações, e nessas, alguns dos exemplos de domínios mais citados são o jurídico, o religioso, o jornalístico e o pedagógico, o que parece demonstrar que estes são settings produtivos e mais consolidados.

Marcuschi (versão mimeo de 2005, do livro Gêneros textuais: constituição e práticas sociodiscursivas) defende que os textos situam-se em domínios discursivos (como ele lembra, em consonância com Bakhtin, 1979, que utiliza o termo "esferas da atividade humana"). $\mathrm{O}$ autor frisa que, assim como é impossível não se comunicar por algum gênero textual, é também impossível não se comunicar por algum gênero textual situado em algum domínio discursivo que confere ao gênero sua força expressiva e adequação comunicativa. Os domínios operam como enquadres globais de superordenação comunicativa subordinando práticas sociodiscursivas orais e escritas que resultam nos gêneros que circulam nesses domínios.

Assim, Marcuschi conceitua domínio discursivo como uma esfera social ou institucional (religiosa, jurídica, acadêmica (instrucional), jornalística, política, militar, industrial, familiar, lazer etc.) na qual se dão práticas que organizam formas de comunicação e respectivas estratégias de compreensão. Essas esferas, como dito, maximizam o surgimento de dados gêneros.

Se adotamos esta noção de domínios, como alavancadores de modelos de ação comunicativa que vão, por sua vez, contribuir para a estabilização dos gêneros, parece apropriado se pleitear a existência de um domínio pedagógico, pois nele podemos reconhecer gêneros bastante recorrentes e estabilizados (tais como aulas, seminários, exames), com propósitos bem definidos.

Todavia, ainda há muito por fazer. Carecemos de trabalhos que mostrem melhor as especificidades desse e de outros domínios, pois tudo leva a crer que se 
BARROS, K. S. M. Sobre o discurso da construção do conhecimento

trata de uma forma relevante de entender as relações entre interação e organização social. No conjunto, estudos detalhados dos domínios, analisados a partir de diferentes critérios de observação, possibilitariam uma melhor compreensão do próprio conceito de domínio discursivo (e de gênero), garantindo mais clareza sobre os gêneros mais produtivos em cada um deles.

Fora da teoria dos gêneros, o conceito pode assumir contornos ainda mais difusos, por exemplo, nos estudos sobre interação eletrônica que costumam contrapor, sem maiores explicações, os domínios real e virtual. Torna-se evidente que seria necessário maior clareza no uso do conceito entre os estudiosos da língua.

Também ainda faltam reflexões que se reportem a conceitos teóricos que compartilham uma área de sobreposição, sendo relevante, por exemplo, identificar as diferenças e semelhanças entre domínio e set/setting - termo bastante usado, por exemplo, nas análises de discurso terapêutico. Ou até mesmo entre domínio e sistemas de gêneros (ver BAZERMAN, 2005, p. 32, que os define como compreendendo os diversos conjuntos de gêneros utilizados por pessoas que trabalham juntas de uma forma organizada). Ou ainda domínio e frame, um dos conceitoschave dos sociointeracionistas que seguem a perspectiva teórica de J.J. Gumperz, já que ambos os termos implicam o conceito de estruturas de expectativas.

Há, também, uma oscilação entre os termos "pedagógico", "científico", "acadêmico" e "instrucional", os quais, dependendo do autor/trabalho, podem estar sendo ou não usados de forma diferenciada. Isso comprova que os limites entre alguns domínios são difusos, mas também aponta para o fato de que existem laços familiares entre domínios ou entre gêneros, de modo que - mesmo com tantas questões a serem ainda resolvidas - parece ser relevante refletir sobre a natureza dessas afinidades.

\section{O domínio pedagógico}

Então, nas linhas que se seguem, vamos nos reportar a alguns aspectos que geralmente são considerados quando analistas discutem gêneros pedagógi$\cos$ (mesmo que eles não usem esta denominação). 


\subsection{Critérios formais}

Como lembram Drew \& Heritage (1992), dentre os estudos publicados sobre o discurso pedagógico, os mais conhecidos e influentes trataram de aspectos formais, já que muitos deles foram realizados por pesquisadores da AC, de linha etnometodológica. Dentre esses estudos pedagógicos, a modalidade estudada foi, claro, a oral, o discurso mais estudado foi o da sala de aula e o aspecto mais discutido foi o da diferença na organização dos turnos (como em MCHOUL, 1978; van LIER 1989; MAYNARD, 1980; SINCLAIR \& COULTHARD, 1975) em relação à conversação casual. Muitos desses estudos sobre a sala de aula se alinham a outros centrados no discurso jurídico, médico, jornalístico na busca por demonstrar a existência de um "discurso institucional", em oposição ao casual. As diferenças, pressupõem os analistas, se dão em função do maior grau de formalidade.

Os estudos que buscam descobrir os "detalhes identificadores" (GARFINKEL, 1981, apud DREW \& HERITAGE, 1992) do discurso institucional diferem dos da teoria dos gêneros principalmente pela suposição básica da existência polarizada de um conjunto de discursos institucionais em oposição a um casual. Há também que se questionar o sentido do que seria "institucional".

Apesar de possíveis objeções, sem dúvida foram os que mais estudaram o discurso pedagógico, daí o motivo de nos referirmos a eles. Além disso, há um pressuposto da ideia de "domínio" na postura de classificação dos discursos em pedagógico, jurídico, médico, jornalístico etc., embora a pergunta deles não seja o que há de comum entre vários gêneros de um domínio, mas o que todos esses "domínios" têm em comum.

\subsubsection{Estrutura dos turnos}

Drew \& Heritage (1992) salientam que esses estudos sobre o discurso institucional - que, como dissemos, focaram a organização diferenciada dos turnos - se mostraram influentes por duas razões.

Primeiro, porque a organização dos turnos é um aspecto central de qualquer interação, e, no discurso institucional, a organização do sistema de troca de turno, com regras de alocação mais rígidas que na casual, seria a prova mais evidente de que os interlocutores reconhecem o caráter "institucional" da interação. 
BARROS, K. S. M. Sobre o discurso da construção do conhecimento

No que se refere a aulas, parece que podemos concordar - mas apenas em parte - com os analistas da conversação sobre a existência de certo grau de rigidez do sistema de distribuição dos turnos. Nossos dados mostram que há aulas mais centradas no professor e menos centradas no professor, daí resultando padrões formais diferenciados de distribuição de turnos. Em outras palavras, é preciso cuidado antes de se descrever aula como bloco único, pois a interação aí é bastante complexa e heterogênea, tanto quanto em conversações casuais.

O que sustentamos é que, no discurso pedagógico - por questões de funcionalidade - há normas bastante claras sobre como deve se dar a interação. Estas normas podem ser explicitadas em momentos de turbulência através de chamadas por parte do professor do tipo: peraí peraí gente; assim a gente não se entende; deixa eu terminar isso aqui; olha assim não dá etc. Geralmente, chamadas do professor deste tipo não são vistas como admoestações, o que comprova que os participantes reconhecem a existência de um propósito pedagógico subjacente à interação que justifica comportamentos considerados ofensivos em outras situações.

Resumindo, no domínio pedagógico, há normas bem definidas quanto à distribuição de turnos, mas que podem ser mais rígidas ou menos rígidas conforme o gênero. É possível que exames orais, por exemplo, possam apresentar estrutura de organização dos turnos diferenciada, em função de estes serem reconhecidos pelos participantes como tendo o propósito mais de teste do que de transmissão de conhecimento. No gênero aula, como em outros, os papéis bem marcados podem ser evocados, deixando marcas formais no texto, como as indicadas acima.

A segunda razão da influência dos estudos pedagógicos na busca do que seria "institucional”, segundo Drew \& Heritage (1992,) refere-se à constatação de que as diferenças sistemáticas no sistema de troca de turnos restringem as oportunidades de participação - o que decorre de direitos diferenciados dos participantes -,que são estereotípicas do discurso institucional. Tais diferenças tornam necessárias especializações e reespecificações das funções interacionais que vão dar margem a uma série de ações e práticas diferentes da conversação casual e que constituiriam, assim, as impressões digitais do discurso institucional.

Consideramos que esta linha de argumentação - a da assimetria - é complexa e de difícil comprovação. Aqui há alguns pontos problemáticos que devem ser observados: primeiro, parte-se de uma concepção de poder como algo estático e não como construído no processo da interação. Segundo, se, numa aula, um parti- 
cipante tem, por um lado, mais direito de conduzir o turno, ele também tem, por outro, a responsabilidade da construção do conhecimento. O professor não está numa sala de aula para exercer seu poder sobre seus interlocutores, mas para ensinar, o que não pode fazer sem a colaboração do aluno, ou seja, o aluno também tem bastante poder. Este equilíbrio de forças dá margem a processos de negociação complexos. Terceiro, não há evidências empíricas fortes que nos permitam relacionar estrutura dos turnos, quantidade de fala e simetria / assimetria.

Assim, não se considera que o domínio pedagógico possa ser a priori caracterizado pela existência de uma assimetria entre os interactantes. O que se pode dizer é que, em maior ou menor grau, o domínio pedagógico tende a apresentar identidades sociais bem marcadas por rotinas bastante específicas, sujeitas a normas consolidadas, mas vulneráveis aos processos interacionais, justificadas em relação às tarefas e à qualidade e eficiência da comunicação. Se necessário, as rotinas e convenções podem ser evocadas em função dos propósitos comunicativos, gerando mudanças nas estruturas de participação (GOFFMAN, 1981) e realinhamentos nos padrões comportamentais.

\subsubsection{Organização sequencial}

Os analistas de interações institucionais, como Drew \& Heritage (1992), Hesler \& Francis (2001), por exemplo, sustentam que o caráter institucional se consolida, geralmente, através de fenômenos sequenciais. Correções e reparos, interrupção, mudança de tópico etc. são usados pelos participantes para gerenciar atividades particulares envolvendo papéis sociais específicos.

No que se refere a aulas, identificamos em trabalhos anteriores à abundância de fenômenos de reformulação: correções e reparos, repetições e paráfrases, paralelismos sintáticos e semânticos são estratégias correntes atualizadas tanto pelo professor quanto pelo aluno ou para argumentar ou para facilitar o processamento.

Obviamente, não se pode argumentar que esses fenômenos caracterizam o domínio pedagógico, já que não são específicos dele, mas sua alta ocorrência evidencia a preocupação com os propósitos comunicativos relacionados à construção do conhecimento. O que equivale a dizer que, metodologicamente, sugerimos o deslocamento do foco de análise da simples identificação de estruturas para a observação dos objetivos a que elas servem. Não parece possível afirmar que 
BARROS, K. S. M. Sobre o discurso da construção do conhecimento

dadas estruturas são determinantes de um domínio. Mas, se as observamos enquanto estratégias dos interlocutores na busca de determinados fins, elas passam a constituir provas empíricas relevantes das orientações dos participantes em relação ao domínio.

Por exemplo, a tríade pergunta - resposta - avaliação / comentário tem sido apontada como específica da sala de aula. Não discutimos se esta é mesmo a estrutura mais comum (achamos que não) nem afirmamos que a interação em sala de aula se dá por tríades, mas podemos nos perguntar sobre o porquê de seu uso. Esta parece ser uma estrutura estereotípica de situações em que há uma atividade instrucional subjacente, atividade esta que é convencional e recorrente. Ela pode ocorrer em outros domínios que envolvem ensino-aprendizagem, por exemplo, no familiar, numa interação entre mãe e filho.

De forma análoga, Maynard (1992), em seu estudo sobre diagnósticos médicos, identifica uma sequência como rotineira: abertura do clínico (opinion-query ou perspective display), resposta do paciente, display, relatório ou confirmação do clínico. Mas também enfatiza que, do ponto de vista das propriedades formais, não é possível afirmar que esta estrutura seja específica ou exclusiva deste set. Como na sala de aula, ela é apenas útil para a realização de certa tarefa, embora esta tarefa não precise ser sempre realizada através dela.

Costuma-se argumentar que a ocorrência de uma estrutura desse tipo implica que uma das partes se coloca numa posição de detentora do conhecimento, perguntando sobre o que já sabe, ou seja, trata-se de uma situação de teste. Mas é preciso lembrar que estruturas tríades do tipo:

A: Que hora vai sair?

B: Às 9 .

A: Ah, às 9 , tá certo.

Ocorrem em qualquer situação e não são vistas como teste. Em outras palavras, o caráter avaliativo só é assim percebido em função do contexto - ou do domínio - em que ocorre.

Retomando: mais produtivo do que buscar identificar estruturas específicas de domínios seria centrar na interpretação que os participantes fazem delas, já que a certos domínios estão relacionadas certas estruturas de expectativa. Esta postura metodológica se mostra também produtiva na observação de outros as- 
pectos formais como organização da estrutura global, escolhas estilísticas, lexicais (ocorrência de termos técnicos) etc.

\subsection{Contextos situacionais de circulação}

Em relação aos contextos situacionais de circulação, a observação mais básica é a de que o domínio pedagógico não pode ser definido em termos de local físico, pois o simples fato de um discurso se dar, por exemplo, numa escola não faz dele pedagógico. Temos que considerar que, por um lado, nem todos os gêneros que circulam na escola podem ser caracterizados como pedagógicos e, por outro, que gêneros prototípicos do domínio pedagógico podem circular em outros ambientes, por exemplo, pode-se ter uma aula de catecismo numa igreja ou numa praça. Esta observação pode parecer trivial, mas o espaço físico tem sido um critério bastante usado, mesmo que implicitamente, em muitos trabalhos.

Nos anos 90, Bernstein publicou algumas ideias sobre o discurso pedagógico, sendo os títulos mais influentes: The social construction of pedagogic discourse (num livro em 1990) e Pedagogy, symbolic control and identity: theory, research, critics (1996). Ele conceitua a sala de aula como "discurso pedagógico" e as práticas de sala de aula como práticas reguladoras que "recontextualizam" os discursos ou conhecimentos sob um princípio do controle institucional (CHOULIARAKI, 1998, p. 5). Alguns estudos sobre gêneros pedagógicos (por exemplo, CHOULIARAKI, 1998) se apoiaram no modelo de Bernstein e, portanto, partem do contexto de circulação como critério definidor para classificação dos gêneros pedagógicos (i.e., todos os gêneros que ocorrem em sala de aula são, por definição, pedagógicos).

Bernstein enfatiza que a ideia do discurso pedagógico se opõe à postura ingênua que vê a sala de aula como um contexto transparente em que vários indivíduos interagem. Com o conceito, ele busca reforçar a visão da sala de aula como um contexto específico, histórica e culturalmente marcado, com suas relações de poder e redes de controle. As comunicações entre participantes são vistas, então, como práticas sociais condicionadas por regras e regulamentos da instituição educacional.

Explicando melhor, o modelo de discurso pedagógico de Bernstein é constituído por três conjuntos de condições que regulam o discurso (conhecimento) pedagógico: regras de distribuição, regras de recontextualização e regras de ava- 
BARROS, K. S. M. Sobre o discurso da construção do conhecimento

liação, mas vou me deter nas duas primeiras, as que ele desenvolve com mais detalhes.

Alguns grupos sociais têm acesso e direito à geração do conhecimento, mas há regras de distribuição que especializam as formas de conhecimento e as práticas nos grupos sociais, no sentido de que um médico, por exemplo, teria mais acesso e direito de gerar conhecimento que um enfermeiro.

As regras de recontextualização organizam a apropriação de um discurso de um site institucional por outro. Para Bernstein, não se pode falar do discurso pedagógico enquanto contexto que produz o material a ser ensinado, o que leva Bernstein a defender que o discurso pedagógico implica que os conhecimentos são constituídos mais que construídos ou discutidos em sala.

O discurso pedagógico é antes um princípio para apropriação de outros discursos gerados em seus campos de produção e que são rearranjados sob uma nova ordem submetendo-os a diferentes princípios de organização e relação para fins de transmissão e aquisição (apud CHOULIARAKI, 1998, p. 8-9; e MACDONALD, 2002, p. 447-467).

É evidente que o modelo é bastante radical nessa delimitação dos discursos, mas pode apresentar uma relevância operacional. Por exemplo, consideremos um livro didático no qual foi inserido um poema de um dado autor. O poema não é, a rigor, o gênero poema, mas algum outro que se insere no âmbito do domínio pedagógico. Há que se observar a coocorrência de gêneros, ou seja, se um poema é seguido de um exercício de compreensão, este poema não é mais só um poema. A questão central é se é adequado, então, considerar que todos os gêneros que estão num livro didático são pedagógicos e, em consequência, que todos os gêneros que circulam por contextos situacionais pedagógicos devam ser considerados pedagógicos. Esta é uma das motivações para considerar que o estudo de domínios (e não só de gêneros isoladamente) pode ser produtivo.

Num artigo sobre Representação da fala e categorização do cliente no discurso da assistência social, Hall, Sarangi \& Slembrouck (1999, p. 541) também operam com o conceito de recontextualização, definido de forma um pouco diferente. Explicitam os autores que recontextualização se refere [...] às várias formas de apropriação, uso e reuso de fala ou texto retirados de um contexto para fazer possíveis formulações em outro. No caso desses autores, a busca é por vestígios (sediments) (um termo que adotaram de SILVERSTEIN \& URBAN 1996) da fala do cliente no discurso da assistência social.

Então, para resumir esta parte: o local físico não é, por si só, um critério definidor do domínio. Mas, metodologicamente, acredito que devemos partir dos 
contextos de circulação para garimpar os gêneros pedagógicos (como nas preocupações, por exemplo, de Scollon et al, 1999, no projeto do discurso público em Hong Kong). Uma característica central parece ser que muitos gêneros são recontextualizados em função de propósitos pedagógicos.

\subsection{Funcionalidade}

Um critério que parece central na definição de qualquer domínio, mas ainda mais no pedagógico, é a função, globalmente identificável como sendo a de construir / transmitir conhecimento. Embora eu tenha me apoiado na funcionalidade em partes do texto ao comentar características de um gênero ou outro, reconheço que é preciso um pouco de cuidado antes de nos empolgarmos muito com a relevância deste critério, pois, mesmo sendo central, ele não é suficiente.

Primeiro, porque é difícil deixar de cair numa circularidade teórica. Um domínio é definido em princípio como pedagógico exatamente porque acreditamos que o objetivo central é o de ensino. Assim, não podemos tentar identificar nos dados a função como um critério definidor do que seja domínio pedagógico.

Segundo, dados reais sempre nos fazem questionar o que parece irrefutável. Nem sempre as transcrições de uma aula - um dos gêneros mais representativos do domínio pedagógico - vão espelhar o propósito da construção do conhecimento. Como disse, esse propósito é definido aprioristicamente por nós, analistas, e pelo que sabemos da instituição escola.

Ademais, nosso consenso em relação aos objetivos se deve ao foco da maioria dos estudos: o discurso do professor, quase sempre visto isoladamente, que é, de fato, mais orientado para um fim. Mas, já na produção linguística do aluno, este objetivo básico não fica tão aparente. A menos que se busque, na produção do aluno, os vestígios (nos termos de Hall, Sarangi \& Slembrouck 1999) do discurso de sala de aula, fica difícil caracterizar os textos dos alunos como pedagógicos.

Pode-se argumentar que, em sala de aula, o professor tem papel determinante. Mas, de qualquer forma, a busca da transmissão do conhecimento fica vulnerável aos processos de negociação que emergem na interação e, quase sempre, o propósito central (de responsabilidade do professor) precisa ser "quebrado" em vários outros ao longo da interação.

Há que considerar, ainda, que as análises de gêneros como textos de alunos, discussões acadêmicas (fora da escola) ou exames orais deixam dúvidas quanto ao grau de generalização desta função básica do domínio pedagógico. 
BARROS, K. S. M. Sobre o discurso da construção do conhecimento

Em síntese, a única afirmação que parece pacífica é a de que, no domínio pedagógico, os discursos podem estar orientados para um fim específico. Por sua falta de peculiaridade, tal afirmação não basta para a definição do domínio. É necessário que examinemos mais detalhadamente cada gênero considerando todos os vetores de variação. Propõe-se que a análise seja filtrada pelo olhar dos interactantes, deslocando a observação do texto em si para o comportamento dos indivíduos. No contexto do domínio pedagógico, a análise empírica deve, primeiro, salientar a conduta dos participantes na organização da interação para, depois, ver como essas conduta e organização englobam orientações que são especificamente pedagógicas ou em respostas às normas pedagógicas.

\section{Características recorrentes em gêneros do domínio pedagógico: alguns exemplos}

Exemplo 1 (IAP, 6a , MJ) - produção textual de aluno

\section{Dengue}

Dengue é uma doênça transmitido pela picada dos mosquitos aedes aegty ou esdes abopetus, os sintomas mais facil para combater o dengue: Fauta de apeti, dores de cabeça e na articulação, dor nos olhos, fraqueza, vomito, cançaso, febre alta, mancha avermelhadas no corpo etc.

As pessoas fazem muita queicha porque o governo não bota os carros "Fumaçer" nois todos devemos ter cuidado com essa doença e pode até matar os povos devem ter cuidado com esse mosquito que ele acumula água em garrafas de boca para cima que devem ficar de boca para baixo para não acumula água. Dengue ou você colabora ou o Dengue piora.

Tanto na abertura quanto ao longo da redação, o aluno parece preocupado em demonstrar conhecimento técnico, mencionando:

- O mosquito que transmite a doença - Dengue é uma doênça transmitido pela picada dos mosquitos aedes aegty ou esdes abopetus (parágrafo 1). Note-se que o aluno dá mais de uma opção, usando "ou";

- o que fazer para evitar - As pessoas fazem muita queicha porque o governo não bota os carros "Fumaçer" (parágrafo 2). Observe-se as estratégias 
múltiplas de sinalização do termo "fumacê" (letra maiúscula, sublinhado, aspas), salientando conhecimento.

- como este mosquito se reproduz - que ele acumula água em garrafas de boca para cima (parágrafo 2);

- os sintomas - Fauta de apeti, dores de cabeça e na articulação, dor nos olhos, fraqueza, vomito, cançaso, febre alta, mancha avermelhadas no corpo etc. (parágrafo 1).

Em gêneros do domínio pedagógico, estão presentes regras técnicas específicas que se concretizam em marcas formais, como o emprego de termos técnicos e a organização textual. $\mathrm{O}$ uso de listas (parágrafo 1) busca preencher a expectativa que o aluno acha que o interlocutor tem em relação a ele: uso de precisão e completude informacional, pois esta é uma característica de outros textos pedagógicos usados para construção do conhecimento (cf. exemplos 2 e 3).

Exemplo 2: texto de livro didático

Você estudou no capítulo anterior que a superfície terrestre possui quatro formas fundamentais de relevo.

Essas quatro formas fundamentais de relevo são:

- as montanhas;

- os planaltos;

- as planícies;

- as depressões.

Neste capítulo, vamos identificar as principais formas de relevo do território brasileiro. Para isto, observe o mapa e leia com atenção o texto a seguir.

Você nota que a forma de relevo predominante no Brasil é o planalto.

Este texto apresenta similaridades com a interação que ocorre em sala de aula. $\mathrm{O}$ autor se coloca na posição do professor, dirigindo-se diretamente ao alunoleitor: você estudou; você nota, como um professor costuma fazer numa aula. Ele 
BARROS, K. S. M. Sobre o discurso da construção do conhecimento

tenta envolver o leitor como numa interação: vamos identificar, observe, leia. Utiliza repetição excessiva, um recurso mais característico da fala, demonstrando dúvida em relação à capacidade de compreensão do leitor:

$\begin{array}{llll}\text { possui } & \text { quatro } & \text { formas fundamentais de relevo } & \\ \text { essas } & \text { quatro } & \text { formas fundamentais de relevo } & \\ \text { as principais } & & \text { formas de relevo do território } & \text { brasileiro } \\ \text { nota que a } & & \text { forma de relevo... } & \text { no Brasil é }\end{array}$

Exemplo 3: lista na fala do professor.

P: mas são muitos os agentes antissépticos cientificamente estudados que dão bons resultados nesses casos água oxigenada (.) permanganato de potássio (.) mercúrio (.) mercúrio cromo (.) tintura de iodo (.) iodofórmio (.) creolina (.) o próprio álcool (.) etecetera

Fenômenos como repetição, paráfrase, correção são bastante recorrentes, e tais características parecem baseadas na pressuposição de que aprender é memorizar.

Exemplo 4: aula, fala da professora (aula de OSPB)

P RIQUEZA e renda [...] pesquisaram? (...) a diferença?

viram a diferença? [...]

então (.) é:: riqueza (...) e renda (...)

então o que é riqueza o que é renda?

A riqueza é [...]

Em vários momentos da aula, a professora retoma a pergunta:

bem (...) bem (...) então (...) veja (...)

quem pesquisou essa questão?

o que é riqueza o que é renda? 
P mas (...) então eu queria que vocês vissem ainda essa questão da renda e da riqueza (..) o que é renda o que é riqueza?

P mas ainda (.) ((bate na mesa)) insistindo nessa questão o que é a renda o que é a riqueza do nosso país?

Este tipo de repetição do professor tem como função marcar o tópico, assim orientando o aluno sobre o que está sendo falado. Esta explicitação exagerada do tópico que aparece na fala do professor também vai ocorrer nas redações dos alunos.

Exemplo 5: produção textual de A - Texto 103.

falando sobre as festas juninas: São os meis dos santos que e são joão santo Antonio e São Pedro: todo mundo tem que comemorar os dias deles: com bomba com todo festejo e tem que faz: a foqueirinha: que e a comemoração deles: e tem mais vivia vivia Santo Antonio: vivia vivia São João vivia vivia São Pedro: com festejo e balões: sempre quando vai jegando os dias dos tres santo que e são João: e São Pedro e Santo Antonio: os meninos; junto com as meninas vão ficando alegre: Porque vão dançar a quadrilha $[\ldots]$

e eu: Gosto dos santo do mundo todinho e presponente santo Antônio e São Pedro e São João.

Observe-se que o aluno repete (no exemplo, em itálico) o nome dos santos em cada parte do texto - na introdução, no desenvolvimento e na conclusão. Ao longo de toda sua redação ele vai indicando que está falando sobre o tópico estipulado (as festas juninas), já que permanecer no tópico é fundamental para uma boa nota.

Enunciados meta são recorrentemente utilizados para assinalar introdução e mudança tópicas, tanto pelo professor quanto pelo aluno (exemplos 6 e 7). 
BARROS, K. S. M. Sobre o discurso da construção do conhecimento

Exemplo 6: aula, fala de professor

P vamos falar sobre os sentidos em geral

eu vou citar $[\ldots]$ vou citar os sentidos certo?

e vou também falar sobre os órgãos responsáveis [...]

Exemplo 7: redação do aluno

falando sobre as festas juninas: São os meis dos santos que e são joão santo Antonio e São Pedro:

\section{À guisa de conclusão}

Além das observações já resumidas ao longo do trabalho, outras observações teóricas / metodológicas mais gerais incluem:

A busca por definição do domínio pedagógico (ou qualquer domínio) deve partir de diferentes perspectivas de observação, considerando aspectos formais, funcionais e os contextos de circulação. Vistos isoladamente, nenhum desse conjunto de critérios parece ser suficiente para a definição de todos os gêneros de um domínio pedagógico. O que equivale a dizer que, dependendo do gênero, um critério pode ter um peso maior para sua classificação como pedagógico. É urgente se (re)pensar o conceito de domínio em base menos intuitivas, através da análise detalhada de gêneros que parecem compartilhar características (não só formais) comuns. A pesquisa deve se iniciar pelo contexto de circulação, observando neles os gêneros mais produtivos. A análise deve priorizar o ponto de vista dos interactantes, observando as marcas que deixam no discurso.

As análises, embora limitadas, também evidenciam a pertinência - pelo menos no caso do domínio pedagógico - de não se trabalhar com os gêneros isoladamente, mas com os gêneros em domínios. Tudo indica que os textos produzidos pelos alunos em situação de sala de aula - mesmo os textos escritos sofrem influência direta das características deste evento em que são produzidos. E que a escrita do aluno sofre influência dos outros gêneros que circulam em sala de aula. 


\section{Referências}

BAZERMAN, C. Gêneros textuais, tipificação e interação. Tradução Judith Hoffnagel DIONÍSIO, A.; HOFFNAGEL, J. (Org.). São Paulo: Cortez. 2005.

BAKHTIN, M. M. Marxismo e Filosofia da Linguagem. Tradução Michel Lahud; Yara Frateschi Vieira. São Paulo: Hucitec. 1979.

BERNSTEIN, B. The social construction of pedagogic discourse. In: Class, codes and control. v. IV: the structuring of pedagogic discourse. Londres: Routledge, 1990, p. 165-218.

. Pedagogy, symbolic control and identity: theory, research, critics. Londres: Taylor \& Francis, 1996.

BIBER, D. Variation across speech and writing. Cambridge: CUP, 1988.

CHOULIARAKI, L. Regulation in "progressivist" pedagogic discourse: individualized teacher-pupil talk. Discourse \& Society, v. 1, n. 9, p. 5-32, 1998.

DREW, P; HERITAGE, J. (Org.). Talk at work: interaction in institutional settings. Cambridge: CUP, 1992.

GOFFMAN, E. Forms of talk. Philadelphia: University of Philadelphia Press, 1981.

HALL, C; SARANGI, S; SLEMBROUCK, S. Special representation and the categorization of the client in social work discourse. Text. v. 4, n. 14, p. 539-570, 1999.

HESLER, S; FRANCIS, D. Is institutional talk a phenomenon? Reflections on ethnomethodology and applied conversational analysis. In: MCHOUL, A; RAPLEY, M. (Org.). How to analyse talk in institutional settings: a casebook of methods. Londres: Continuum, 2001, p. 206-217.

MACDONALD, M.N. Pedagogy, pathology and ideology: the production, transmission and reproduction of medical discourse. Discourse \& Society, Vol. 13, No. 4, 2002, p. 447-467.

MARCUSCHI, L. A. Gêneros textuais: constituição e práticas sociodiscursivas. Versão mimeo. 2005.

MCHOUL, A. the organization of turns at formal talk in the classroom. Language in Society, 7, p. 183-213. 
BARROS, K. S. M. Sobre o discurso da construção do conhecimento

MAYNARD, D. Interaction and asymmetry in clinical discourse. American Journal of Sociology. v. 97, n. 2, set 1991, p. 448-495, 1992.

MAYNARD, D.W. Placement of topic changes in conversation. Semiotica, 30 (3/ 4), 1980, p. 263-290.

SCOLLON, R. et al. Blurred genres and fuzzy identities in Hong Kong public discourse: foundational ethnographic issues in the study of reading. Applied Linguistics. v. 20, n. 1, p. 22-43,1999.

SILVERSTEIN, M; URBAN, G. The natural history of discourse. In: (Org.). Natural histories of discourse. Chicago: University of Chicago Press, 1996, p. 1-20.

SINCLAIR, J.Mc; COULTHARD, R.M. Teacher talk. Oxford: Oxford University Press, 1975.

VAN LIER, L. The classroom and the language learner. Londres: Longman, 1989.

\begin{abstract}
Many genre analysts claim the existence of a pedagogical domain. This makes defining which genres belong to such a domain and what they have in common. The features most frequently shared by the genres would constitute the basic characteristics of the pedagogical domain. This work aims to identify the characteristics in three kind of texts commonly found in pedagogical contexts: student compositions, texts appearing in textbooks and teacher talk. Before the analysis itself we discuss some of the criteria which have been used by analysts in the characterization of pedagogical genres.
\end{abstract}

Keywords: academic discourse; discursive domain; pedagogical genres. 